\title{
Development of Automatic Fire Detection and Rescue System using GSM
}

\author{
Nandhini $\mathbf{P}^{1}$, Rathika $\mathbf{M}^{2}$, Revathi $\mathrm{L}^{3}$, Ragavi $\mathbf{P}^{4}$ \\ Assistant Professor, Department of ECE, Velalar College of Engineering and Technology, Erode, Tamilnadu ${ }^{1,2,3,4}$
}

\begin{abstract}
Train transport is major role in everyone's life. So people's expectation will be a safe journey. Train journey will be more comfortable than any other means of transport, so most of the people prefer travelling through train. Fire accidents may occur at unexpected situations in train and so handling those problems will be difficult to humans. In this paper, we introduce automatic fire detection and rescue system based on Wireless Sensor Network (WSN) technology to monitor continuously and observe the range of temperature and gas from respective sensors. When the fire is detected, the information gathering unit reports the monitored information to the surveillance centre via Global System for Mobile Communication (GSM) and necessary help is arrived at the site. Using an automatic sprinkler system the fire can be put off automatically and the emergency window will be opened automatically with the help of the motor interfaced with the module. Therefore, passengers can be rescued through this window.
\end{abstract}

Keywords: WSNs, GSM, Automatic Sprinkler System, Temperature Sensor, Gas sensor.

\section{INTRODUCTION}

The trains are moderate vehicles used for transporting people's and goods. Mostly, pupil prefer train journey for long distance and the train fares are also very cheap. Fire accidents are very rare in trains because there are many prohibitions for smoking and carrying inflammable materials. Trains are also checked at various stations to ensure the safety journey of passengers. However, at sometimes there may be some failure in the maintenance system due which fire may occur. Fire accidents are most serious disasters to human lives and to the government property. Fire accidents in train can make several human loss and serious injuries to them.

So there is a need to a system that monitors every compartment and when the fire is detected the system should alert the passengers by alarming and report to the driver to stop the train and inform the higher officials about the fire accident and the system should also extinguish fire automatically by using water sprinkler system. This system also provides automatic opening of emergency windows through which passengers can be rescued. In order to satisfy all those requirements, wireless sensor network based on GSM technique is proposed. This system is used for monitoring, fire sprinkling, cautioning, and preventing fire in running trains.

The fire may be caused due to short circuits in electrical wires, carrying diesel, petrol, gas stoves and smoking in train. This proposed system keep on monitoring the gas levels and temperature in every compartment and if they exceeds the default level, then message will be sent to the driver about these levels via GLOBAL SYSTEM FOR MOBILE MONITORING (GSM) and necessary steps are taken. This system can monitor real-time related parameters such as temperature and humidity in every compartment.

\section{LITERATURE REVIEW}

Deepika K and Yuvaraju M paper titled as "Wireless Sensor Network Based on GSM for Automatic Fire Detection and Rescue System in Train", the proposed method in this paper was the fire will be detected using wireless networks such as gas sensor and temperature and the message will be transmitted to the driver using GSM system and fire will be extinguished using water sprinkler. When the gas level and the temperature in the compartment exceeds the particular level, the message will be transmitted to the driver and he will stop the train. This system uses PIC16F877A microcontroller.

Pitchai Ramasamy R, Praveen Kumar M, Sarath Kumar S, Raghu Raman R paper titled as “Avoidance of Fire Accident on Running Train Using Zigbee Wireless Sensor Network", this system detects the fire in running train using wireless sensors and transmits the message to the driver via Zigbee module. Zigbee is a short range communication module and it is very cheaper. Since the message is transmitted to the driver, Zigbee suites the best. This system detects fire based on parameters like temperature, humidity in every coach. From the information collected by the sensor system, decisions for fire fighting, alarming and automatic water sprinkling system can be made quickly by the engine driver. 
Ramesh S paper titled as "Rail Parameters Monitoring for the Fire Safety System in the Compartments Using Automation Technology", in this proposed method some parameters such as smoke, temperature, humidity etc are monitored continuously in the compartments by using wireless sensors for ensuring fire safety in train.

Ko Yin, Junchang Jiang paper titled as "Application of Fire Monitoring and Personnel Evacuation in Subway Station Based on Wireless Sensor Network", this paper made a trail application of Wireless Sensor Network technology into fire monitoring and personnel evacuation based on some advanced algorithms. This system worked effectively in monitoring fire and rescuers to evacuate the subway station fire.

Ramprasath P S, Sairam K, Sivaraman N, Prof D Shanthi Chelliah, "Rapid Fire Intimation System for Railways Using Wireless Sensor Network", this proposed method will detect fire using zigbee module and sends the location of the train, train number, compartment, time, position and speed to the nearest fire station and hospital using GPS. It also sends an emergency signal to the engine driver to stop the train.

\section{EXISTING METHOD}

There are few existing methods that helps to detect the fire using some wireless sensors and transmits the message to the engine driver about the fire and they may take tend to stop the train and the fire can be extinguished using automatic water sprinkler. The fire in these systems are detected using gas sensor and temperature sensor. If the gas or temperature value exceeds the prescribed value, then the driver will receive the message about these levels. The message is sent to the engine driver using GSM module. If the fire is detected, the message will be sent to the engine driver to stop the train and the fire will be extinguished using automatic water sprinkler.

\section{PROPOSED METHOD}

In our proposed method, the gas and the temperature sensor will be keep on monitoring the levels. If the fire is detected, a message will be sent to the engine driver and the authority to stop the train, the fire can be extinguished using automatic water sprinkler system and the passengers can be rescued through emergency window which opens automatically whenever there is a fire accident. This system uses gas sensor and thermistor to monitor the levels of gases and temperature and message is transmitted using GSM module. PIC16F877A is used as a microconntroller and the sensors are interfaced with it. A motor is interfaced with a microcontroller to enable automatic emergency window opening.

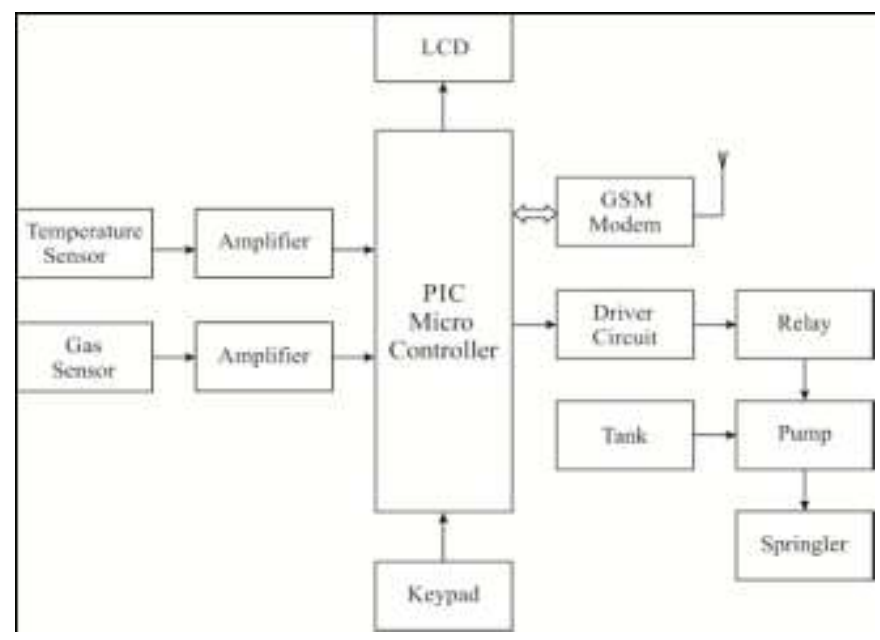

Fig.1 Block Diagram

\section{HARDWARE DESCRIPTION}

\section{A. PIC16F877A :}

The PIC microcontroller PIC16F877A is one of the most renowned microcontrollers in the industry. This controller is very convenient to use, the coding or programming of this controller is also easier. One of the main advantages is that it can be write-erase as many times as possible because it use FLASH memory technology. It has a total number of 40 pins and there are 33 pins for input and output. PIC16F877A is used in many pic microcontroller projects. PIC16F877A also have many applications in digital electronics circuits. 


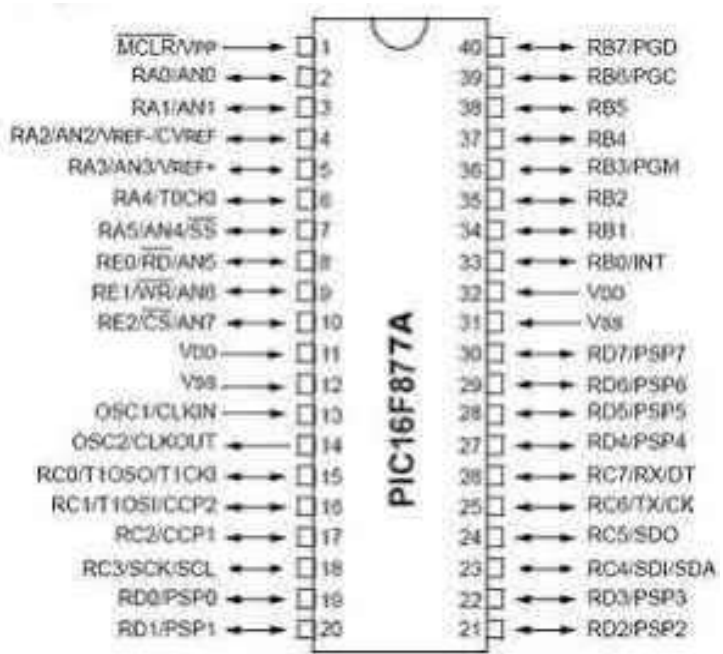

Fig.3 PIC16F877A pin diagram

PIC16F877A finds its applications in a huge number of devices. It is used in remote sensors, security and safety devices, home automation and in many industrial instruments. An EEPROM is also featured in it which makes it possible to store some of the information permanently like transmitter codes and receiver frequencies and some other related data. The cost of this controller is low and its handling is also easy. Its flexible and can be used in areas where microcontrollers have never been used before as in coprocessor applications and timer functions etc.

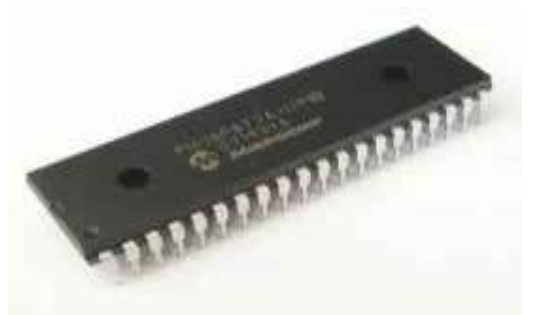

Fig.2: PIC16F877A

\section{FEATURES:}

- Only 35 single word instructions.

- Operating speed: DC-20MHz clock input.

- 8 kBytes Flash Program Memory.

- 368 Byte RAM Data Memory.

- 256 Byte EEPROM Data Memory.

- In-circuit serial programming.

- Synchronous serial port with SPI and $\mathrm{I}^{2} \mathrm{C}$.

- Eight channel, 10-bit Analog to Digital Converter(ADC)

- Universal Synchronous Asynchronous Receiver Transmitter(USART)

\section{B. TEMPERATURE SENSOR :}

Temperature sensor is a device which senses variations in temperature across it. Thermistor is a basic temperature sensor that can be used for experimental purpose. It give the readings in centigrade (degree Celsius) since its output voltage is linearly proportional to temperature. It uses the fact that as temperature increases, the voltage across diode increases at known rate (actually the drop across base-emitter junction of transistor.

Temperature sensor has three terminals and required Maximum of $5.5 \mathrm{~V}$ supply. This type of sensor consists of a material that performs the operation according to temperature to vary the resistance. This change of resistance is sensed by circuit and it calculates temperature. When the voltage increases then the temperature also rises. We can see this operation by using a diode.

Temperature sensors directly connected to microprocessor input and thus capable of direct and reliable communication with microprocessors. The sensor unit can communicate effectively with low-cost processors without the need of A/D converters. 


\section{GAS SENSOR :}

Sensitive material of MQ-13 gas sensor is $\mathrm{SnO}_{2}$ which with lower conductivity in clean air. When the target flammable gas exist, the sensor's conductivity gets higher along with the gas concentration rising. Users can convert the change of conductivity to correspond output signal of gas concentration through a simple circuit. This sensor can detect kinds of flammable gases, especially has high sensitivity to LPG (propane). It is a kind of low-cost sensor for many applications. It is widely used in domestic gas leakage alarm, industrial flammable gas alarm and portable gas detector.

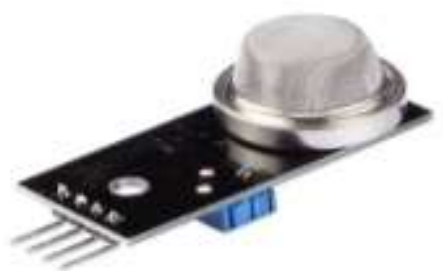

Fig.4 : Gas Sensor

\section{GLOBAL SYSTEM FOR MOBILE COMMUNICATION(GSM)}

GSM refers to Global system for mobile communication which is the key factor in this paper to inform about the where-about of the fishermen in the vast seas. A common European mobile telephone standard that would formulate specifications for a pan-European mobile cellular radio system operating at $900 \mathrm{MHz}$. A GSM modem is a wireless modem that works with a GSM wireless network.GSM also make sure that all the communication made between networks are secured and protected from intruders and frauds.

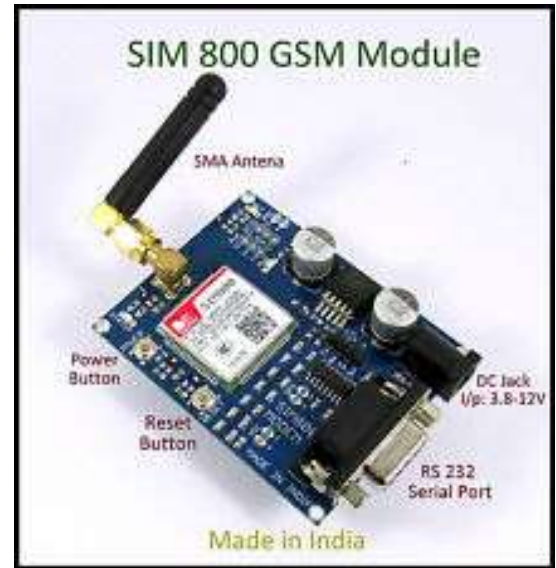

Fig.5 SIM800 GSM Module

In the GSM, information is sent to the mobile phones of the family members through SMS, informing them about the status. In case the boat is lost due to rough conditions of the sea (or) intentional crossing of the border is done, then the information is immediately sent to the border security and the necessary action is taken.

\section{E. BUZZER}

A buzzer or beeper is a signaling device, usually electronic, typically used in automobiles, household appliances and sounds a warning in the form of a continuous or intermittent buzzing or beeping when mismatch occurs.

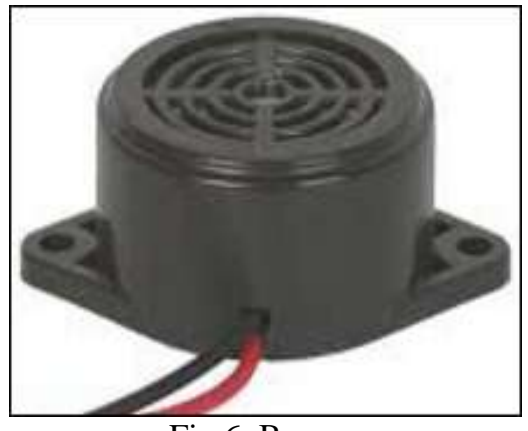

Fig.6. Buzzer 


\section{F. RELAY}

A relay is an electromagnetically operated switch and made up of an electromagnet and a set of contacts. Relays control one electrical circuit by opening and closing contacts in another circuit..Relays are found hidden in all sorts of devices.

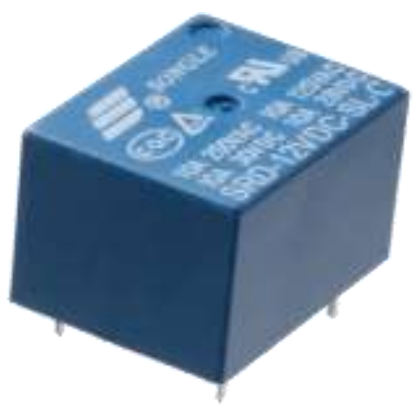

Fig.7 Relay

\section{G. DC MOTOR}

DC motor is electric motor that runs on direct current directly. It converts direct current electrical power into mechanical power.DC motor used to change the direction of current flow and motor voltage is proportional to speed.

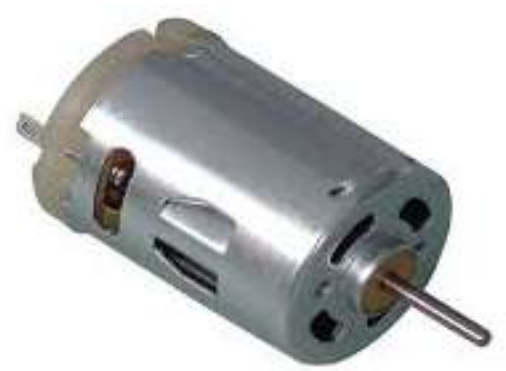

Fig.8 DC Motor

\section{DC motor 6/9V}

Item Specification

Rated Voltage 6V DC

Operating voltage $1.5-6.5 \mathrm{~V}$ DC

starting current $\leq 5 \mathrm{~A}$

\section{ADVANTAGES:}

- Low initial cost

- High reliability

- Simple control of motor speed

\section{H. LCD DISPLAY}

LCD stands for Liquid Crystal Display; this is an output device with a limited viewing angle. The choice of LCD as an output device was Because of its cost of use and is better with alphabets when compared with a 7-segment LED display. We have so many kinds of LCD today and our application requires a LCD with 2 lines and 16 characters per line, this gets data from the microcontroller and displays the same.

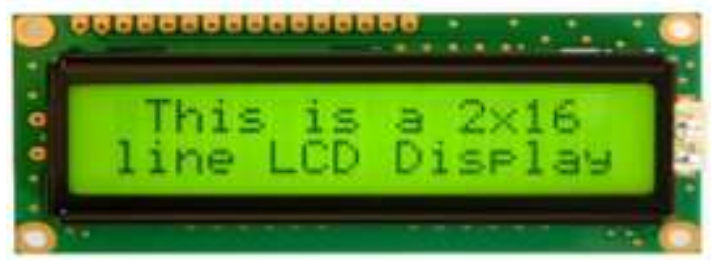

Fig.9 LCD display $2 \times 16$

In recent years the LCD is finding widespread use replacing LED's. This is due to the following reasons:The declining prices of LCD's. The ability to display numbers, characters and graphics. 


\section{CONCLUSION}

Thus this proposed system helps to prevent fire accidents in train and passengers can have a safe journey. This system may detect fire using wireless sensorsand transmits meaasage to the engine driver about the fire through GSM module and he may stop the train. The fire can be extinguished automatically with the help of water sprinkler and passengers can be rescued through emergency window which opens automatically when the fire is detected.

\section{REFERENCES}

[1] Deepika K, Yuvaraju M, "Wireless Sensor Network Based on GSM for Automatic Fire Detection and Rescue System in Train", in International Journal of Engineering Research \& Technology(IJERT), ISSN: 2278-0181 Volume 4 Issue 11, November-2015

[2] Yeon-sup lima, Jaehyerk choi, Scongho cho, Chong-kwon kim and yong woo Lee, "A Fire Detection and Rescue Support Framework with Wireless sensor Networks", in 2007 International Conference on Convergence Information Technology.

[3] R. Pichai Ramasamy, M. Praveen Kumar, S. Sarath Kumar and R. Raghu Raman, "Avoidance of Fire Accident On Running Train Using Wireless Sensor Network", in International Journal of Information and Computation Technology, ISSN 0974-2239 Volume 3, member 6 (2013).pp.583-592.

[4] Manoj Kumar Tgagi, Bangalore Raviteja, "The Implementation of Automatic Fire Rescuing and Information System in a train Using Zigbee and Sensors Network", International Journal of Computer Trends and Technology(IJCTT)- volume issues-May 2013.

[5] Santhoshi Shingirikonda, K. Vanisree, "Development of an Automated Rescue system", in International Journal of Engineering Trends and Technology (IJETT)- volume 4, Issue 8-August 2013.

[6] Srajan Saxene, "Accident Identification with Automatic Ambulance Rescue System”, in International Journal of Scientific and Engineering Research, Volume 5, Issue 9, September-2014.

[7] S. Ramesh, "Rail Parameters Monitoring for the Fire Safety System in the Compartments Using Automation Technology", Global Journal of Scientific and Electronics Engineering Research, Volume 14 Issue 3 version 1.0 year 2014.

[8] Kalpana Sharma, Jagdish Kumawat, Saurabh Maheswari, Neeti Jain, "Railway Security System Based on Wireless Sensor Networks: State of the Art', in International Journal of Computer Applications (1975-8887) Volume 96- No 25, June 2014.

[9] Ko Yin, Junchang Jiang, "Application of Fire Monitoring and Personal Evaction in Subway Station Based on Wireless Sensor Network" in IEEE 2014.

[10] Ramprasath P S, Sairam K, Sivaraman N, Prof D. Shanthi Chelliah, "Rapid Fire Intimation System for Railways Using Wireless Sensor Network', in International Journal of Advanced Research In Electronics And CommunicationEngineering (IJAREE) volume 11, Issue 3, March 2015.

[11] Muhammad Shlihin Ahmad Azmil, Norusuzila ya'acob, Khairul Nizar, Suzi Serio Samin, "Wireless Fire Detection Monitoring System for Fire And Rescue Application", in 2015 IEEE 11th International Colloquium on Signal Processing and its Applications (CSPA 2015).

[12] P. Poobalan, N. NAresh, G. Rajesh, B. MAheswaran, Aswin Vinod, "GPS and GSM based Accident Location Indicator and Rescue System", in Journal of the International Association of Advanced Technology and Science(JIAATS) volume 16, March 2015. 